\title{
Toxicovigilance II: A survey of the spectrum of acute poisoning and current practices in the initial management of poisoning cases admitted to South African hospitals
}

D J H Veale, Dip Pharm, BSc Hons, MSc, PhD; C A Wium, BSc, BSc Hons, MSc; G J Müller, BSc, BSc Hons, MB ChB, MMed, PhD

Tygerberg Poison Information Centre, Department of Medicine, Faculty of Health Sciences, Stellenbosch University and Tygerberg Academic Hospital, Parow, Cape Town

Corresponding author: D J H Veale (djhveale@gmail.com)

\begin{abstract}
Background. Initial management of acute poisoning in South African (SA) hospitals such as gastric decontamination and use of antidotes has not been evaluated relevant to current international guidelines.

Objectives. The objective of this study was to conduct a toxicovigilance survey of SA hospital admissions to assess the spectrum of acute poisonings, current practices in gastric decontamination, and use of antidotes in the management of acute poisoning.

Methods. A survey was undertaken based on acute poisoning admissions to Tygerberg Academic Hospital (TAH) as well as hospital-based poisoning consultations with the Tygerberg Poison Information Centre (TPIC) over 1 year to investigate trends in admissions and the initial management of hospital admissions for acute poisoning. TAH admission details and TPIC consultation forms for hospital-based cases were analysed for patient demographics, causes of poisoning, gastric decontamination measures and use of antidotes.

Results. There were 662 admissions to TAH and 2459 hospital-based TPIC consultations. Paracetamol and cholinesterase inhibitors were the most common exposures in both studies. Gastric decontamination measures were employed at TAH in $47.7 \%$ of cases and in $5.3 \%$ of hospital cases reported to the TPIC. Of these, $67.4 \%$ in the TAH study and $26.1 \%$ in the TPIC study did not comply with international guidelines. $\mathrm{N}$-acetylcysteine was administered inappropriately in $22.1 \%$ of the paracetamol poisoning cases at TAH and in $1.6 \%$ in the TPIC study. Atropine was administered unnecessarily in 12 of 30 TPIC cases.

Conclusion. This study has identified the need for directed training on gastric decontamination measures and use of antidotes and, combined with the previous study, has identified national trends in poisoning.

S Afr Med J 2013;103(5):298-303. DOI:10.7196/SAMJ.6648
\end{abstract}

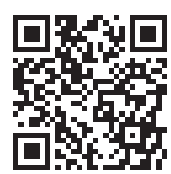

In order for poison information centres (PICs) to fulfil their toxicovigilance role, it is essential that they interact with medical facilities that provide care for poisoned patients in order to facilitate the necessary updating and expansion of information on diagnosis, treatment and general patient management of poisoning cases. ${ }^{[1,2]}$ Case data received by PICs from enquiries from emergency wards, local hospitals or clinics may assist in the assessment of the current quality of care at these facilities and serve to alert authorities regarding the need for directed updated training on the initial management of poisoning. A cornerstone in the initial management of poisoned patients has been the use of gastrointestinal decontamination measures in the emergency room to prevent absorption of poisons. PICs are expected to advise medical professionals on these procedures as well as on the use of antidotes. ${ }^{[3]}$ A series of guidelines on the efficiency and validity of gastrointestinal decontamination procedures were published in order to assist physicians in deciding when and how these measures should justifiably be implemented..$^{[3-8]}$ Although investigated elsewhere, standard procedures currently employed in the initial management of acute poisoning in South African (SA) hospitals, such as gastric decontamination and use of antidotes, have not been evaluated relevant to current international guidelines.

Data on actual hospital admissions would be expected to provide additional data of epidemiological value such as the actual incidence of admissions for acute poisoning as well as morbidity and mortality rates. These data would be expected to provide details of the more severe exposures to poisonous substances. Details such as the initial management of poisoning cases, the most common presenting clinical features of the toxic exposures, utilisation of toxicology laboratory services and intensive care facilities could assist hospital administrators in ensuring optimal service delivery. Knowledge of the implementation of interventions that might have resulted in a more favourable outcome could also be of great benefit. There have been no studies in SA on combined hospital and PIC data across all age groups.

A recently completed PIC survey of poisoning data from telephonic consultations with the Tygerberg Poison Information Centre (TPIC) has provided some current epidemiological data on poisoning in SA in order to investigate evolving trends in poisoning in the country. ${ }^{[9]}$ The objective of this study was to complete the collection of toxicovigilance epidemiological data by examining hospital admissions data as well. A survey of the spectrum of cases of acute poisoning presenting to hospitals and current practices such as gastric decontamination and use of antidotes in the initial management of acute poisoning in SA hospitals was undertaken. All hospital-based calls to the TPIC, as recorded in the previous study, ${ }^{[9]}$ were identified and compared with admissions data from Tygerberg Academic Hospital (TAH) over a period of a year in order to provide qualitative and quantitative information on national trends in hospital admissions for poisoning, the current spectrum of acute poisoning cases presenting to SA hospitals, gastric decontamination 
procedures employed, and the use of $\mathrm{N}$-acetylcysteine (NAC) and atropine as antidotes.

\section{Methods}

The TPIC and the adjoining 1 310-bed TAH, situated in Parow, Cape Town, were the study sites. TAH is the largest hospital in the Western Cape and the second-largest hospital in the country. About 60000 patients are admitted annually. In addition to its service to patients in the local catchment area, it serves a large number of secondary hospitals as a state tertiary referral hospital and is the academic hospital to the Stellenbosch University Faculty of Health Sciences. The hospital Toxicology Laboratory is situated on the same premises as the TPIC.

The TAH admissions survey was conducted based on daily visits by TPIC consultants to emergency wards and intensive care units (ICUs) for a period of 1 year (1 August 2008 - 31 July 2009). Admission details for all patients admitted with acute poisoning were recorded daily, and where applicable patients were questioned and examined regarding the toxic exposure and clinicians were consulted regarding management of the poisonings. All data were analysed as in the previous paper ${ }^{[9]}$ as well as for toxicology laboratory requests and transfer to high care (ICU). International guidelines drawn up by the American Academy of Clinical Toxicology and the European Association of Poisons Centres and Clinical Toxicologists were used to assess the gastric decontamination procedures followed, as well as the appropriate administration of antidotal therapy in paracetamol poisoning. ${ }^{[47,10]}$ Toxicology Laboratory results were examined and linked to each case where applicable.
TPIC hospital data based on telephonic consultations from medical personnel at hospital facilities only (i.e. state clinics, secondary and tertiary hospitals and private hospitals and clinics) for the same period of time were extracted from standard consultation forms, and all data were analysed as outlined previously. ${ }^{[9]}$

'Children' were defined as paediatric patients $<13$ years old. Toxins were classified as in the previous paper. ${ }^{[9]}$ All data were committed to a standard MS Excel spreadsheet and data analysis was performed using descriptive statistics.

\section{Results}

There were 662 admissions for acute poisoning to the adult and paediatric emergency wards of TAH during the study period. They represented $5.7 \%$ of the total admissions to these wards for the period. The TPIC dealt with 2459 hospital-based consultations; $77.7 \%$ of the cases were queries from state hospitals and $22.3 \%$ were from private hospitals. Table 1 illustrates differences in geographical and demographic data when data from these two hospital groups were compared.

As illustrated in Tables 2 and 3, the majority of TAH admissions were of adults, and of these cases $94.6 \%$ were intentional poisonings. Adult cases and adult intentional exposures (81.3\%) also predominated in the TPIC hospital-based study. There was a female predominance among adults and intentional poisonings in both studies (Table 3). Of the children admitted to TAH, $76.1 \%$ were aged $<5$ years, as were $82.8 \%$ in the TPIC study. Accidental poisoning was predominant in children in both the TAH (89.3\%) and TPIC studies (98.4\%), and intentional poisoning occurred only in the 5 - 12-year-old group (Table 3 ). The

Table 1. Differences in geographical and demographic data between Tygerberg Poison Information Centre (PIC) hospital-based case queries from state and private hospitals

\begin{tabular}{lll}
\hline & \multicolumn{1}{l}{ State hospitals (column \%) } & Private hospitals (column \%) \\
\hline Tygerberg PIC hospital-based cases, August 2008 - July 2009 & & \\
$\quad$ Adults & $1301(68.1)$ & $273(49.7)$ \\
Children $<5$ years & $482(25.2)$ & $251(45.7)$ \\
Children $5-12$ years & $127(6.6)$ & $25(4.6)$ \\
Most common provincial distribution of hospital-based case queries & & \\
KwaZulu-Natal & $751(39.3)$ & $123(22.4)$ \\
Western Cape & $545(28.5)$ & $212(38.6)$ \\
Eastern Cape & $175(9.2)$ & $26(4.7)$ \\
Gauteng & $148(7.7)$ & $153(27.9)$ \\
Total cases & $1910(77.7)$ & $549(22.3)$ \\
Total cases in Tygerberg PIC hospital-based study & 2459 & 2459
\end{tabular}

Table 2. Demographic data from the Tygerberg Hospital study and the Tygerberg PIC hospital-based study: Age and gender distribution of cases

\begin{tabular}{|c|c|c|c|c|c|c|}
\hline & \multicolumn{3}{|c|}{ Tygerberg Academic Hospital admissions } & \multicolumn{3}{|c|}{ Tygerberg PIC hospital-based cases } \\
\hline & $\begin{array}{l}\text { Total cases } \\
\text { (column \%) }\end{array}$ & Male (row \%) & Female (row \%) & $\begin{array}{l}\text { Total cases } \\
\text { (column \%) }\end{array}$ & Male (row \%) & Female (row \%) \\
\hline$<5$ years & $121(18.3)$ & $70(57.9)$ & $51(42.1)$ & $733(28.9)$ & $450(61.4)$ & $283(33.2)$ \\
\hline $5-12$ years & $38(5.6)$ & $16(42.1)$ & $22(57.9)$ & $152(6.2)$ & $85(55.9)$ & $67(44.1)$ \\
\hline All children $<13$ years & $159(24.0)$ & $86(54.1)$ & $73(45.9)$ & $885(36.0)$ & $535(60.5)$ & $350(39.5)$ \\
\hline Adults & $503(76.0)$ & $140(27.8)$ & $363(72.2)$ & $1574(64.0)$ & $657(41.7)$ & $917(58.3)$ \\
\hline Total cases (row \%) & 662 & $226(34.1)$ & $436(65.9)$ & 2459 & $1192(48.5)$ & $1267(51.5)$ \\
\hline
\end{tabular}


male/female ratio was 1:2.6 in adults and 1.2:1 in children in the TAH study and 1:1.4 in adults and 1.5:1 in children in the TPIC study. There was a history of previous intention to do self-harm in $10.1 \%$ (67) of all the TAH cases and in $2.5 \%$ of children aged $5-12$ years.

Table 4 shows that in the TAH study the most common categories of poisoning exposures across all age groups were medicines $>$ nondrug chemicals $>$ biological toxins (snakes $=$ spiders $>$ scorpions), and in the TPIC hospital-based study non-drug chemicals $>$ medicines $>$ biological toxins $($ snakes $>$ plants $>$ scorpions $=$ spiders).The most common medicine-related poisonings across all age groups were analgesics $>$ paracetamol $>$ amitriptyline $>$ antihistamine in the TAH study and analgesics $>$ paracetamol $>$ antihistamines $>$ benzodiazepines in the TPIC study (Table 4). In children, $45.9 \%$ of $\mathrm{TAH}$ admissions were medicine-related, and of these $63.0 \%$ were of children aged $<5$ years, whereas $36.0 \%$ of TPIC hospital cases in children were medicine-related, $83.4 \%$ in children aged $<5$ years.

The most common classes of non-drug chemical exposures across all age groups in the TAH study were pesticides $>$ ethanol $>$ irritant/corrosives and in the TPIC hospital-based study pesticides $>$ irritant/corrosives $>$ volatile hydrocarbons (Table 4 ). In both sets of data, the incidence of exposures to non-drug chemicals in children aged $<5$ years was higher than exposures to medicines; paraffin ingestions comprised $23.5 \%$ (16) of non-drug chemical exposures in the TAH study and $3.2 \%$ (14) in the TPIC study. The most common pesticide exposures across all ages involved cholinesterase inhibitors (57.6\%), anticoagulant rodenticides $(22.0 \%)$ and pyrethroids $(6.8 \%)$ in the TAH study and cholinesterase inhibitors (34.1\%), pyrethroids (18.3\%) and anticoagulant rodenticides (17.6\%) in the TPIC hospital study. The TPIC assisted in the identification of aldicarb 'rat poison' as a carbamate and not a long-acting anticoagulant in all the TAH cases and in $81.6 \%$ of the TPIC hospital cases. The TPIC identified amitraz poisoning in 2 of the $3 \mathrm{TAH}$ cases and in $89.1 \%$ of the 46 TPIC hospital cases. In $21.7 \%$ of these TPIC hospital-based cases, the poisoning had been misdiagnosed as organophosphate poisoning and atropine wrongly administered as the antidote.

In the TAH study, 7.9\% (52) of patients presented within 2 hours of exposure to the poisonous substance. Samples were sent to the toxicology laboratory for toxicology screening in $48.8 \%$ (323) of cases; in $66.9 \%$ (216) results were positive. With regard to the severity of poisoning on presentation across all age groups, $25.5 \%$ of patients (169) were asymptomatic (Poison Severity Score (PSS) 0) on admission. Details with regard to the clinical presentation of severe poisonings are set out in Table 5 . The mortality rate was $0.9 \%$, all deaths occurring in adults (Table 5), and $6 \%$ of cases (40) were admitted to ICUs. Cholinesterase inhibitor poisoning was the most common reason for ICU admission $(40.0 \%, 16)$, followed by amitriptyline poisoning $(15.0 \%, 6)$. The severity of poisoning in children on admission was low (32.1\% (51) were asymptomatic), 62.3\% (99) of the children were admitted for overnight observation only and 5.0\% (8) were admitted to an ICU. There were no paediatric deaths.

In the TPIC hospital-based cases, $20.3 \%$ of calls (499) were made to the PIC within 2 hours of the toxic exposure and $11.1 \%$ of patients (275) were asymptomatic (PSS 0) on admission. Details with regard to the severe poisonings are set out in Table 5 . The mortality rate was $0.4 \%$ (all deaths were of adults).

In the TAH study, gastric decontamination was employed in $47.7 \%$ of cases (316). Single-dose activated charcoal was administered to 225 cases (34.0\%); notably, treatment in 59.6\% (134) did not comply with international guidelines. Multiple-dose activated charcoal (MDAC) was administered in $7.7 \%$ of cases (51) although, according to international guidelines, this regimen was indicated in only $17.6 \%$ of cases (9). The equipment and indication for gastric lavage were inappropriate in 34 out of 37 cases and, although no longer recommended, syrup of ipecac was administered to induce emesis in 3 cases. Intravenous NAC was administered inappropriately as the antidote in $30(22.1 \%)$ of the 136 cases of paracetamol poisoning. In 16 cases $(53.3 \%)$ the infusion was started before 4 -hour paracetamol levels were received from the laboratory and when there was no history of a potentially hepatotoxic ingestion. In 22 (73.3\%) of these cases, the infusion was continued even though the 4-hour paracetamol level recorded was below the treatment line. There was also confusion with regard to when blood sampling for paracetamol levels should be taken, and in 4 cases the sample was taken $2-3$ hours after ingestion.

Table 3. Demographic data from the Tygerberg Hospital study and the Tygerberg PIC hospital-based study: Reasons for exposure and distribution by age and gender

\begin{tabular}{|c|c|c|c|c|c|c|}
\hline & \multicolumn{3}{|c|}{ Tygerberg Academic Hospital admissions } & \multicolumn{3}{|c|}{ Tygerberg PIC hospital-based cases } \\
\hline & $\begin{array}{l}\text { Total cases } \\
\text { (column \%) }\end{array}$ & Male (row \%) & Female (row \%) & $\begin{array}{l}\text { Total cases } \\
\text { (column \%) }\end{array}$ & Male (row \%) & Female (row \%) \\
\hline \multicolumn{7}{|c|}{ Intentional exposures (deliberate self-poisoning) } \\
\hline Children $<5$ years & 0 & 0 & 0 & $0(0)$ & $0(0)$ & $0(0)$ \\
\hline Children 5 - 12 years & $17(3.4)$ & $3(17.6)$ & $14(82.4)$ & $14(1.1)$ & $3(21.4)$ & $11(78.6)$ \\
\hline Adults & $476(96.6)$ & $128(26.9)$ & $348(73.1)$ & $1280(98.9)$ & $485(37.9)$ & $795(62.1)$ \\
\hline Pregnancy & & & $9(2.6)$ & & & $38(4.8)$ \\
\hline Total & $493(74.3)$ & $131(26.6)$ & $362(73.4)$ & $1294(52.6)$ & $488(37.7)$ & $806(62.3)$ \\
\hline \multicolumn{7}{|l|}{ Accidental exposures ${ }^{\star}$} \\
\hline Children $<5$ years & $121(71.6)$ & $70(57.9)$ & $51(42.1)$ & $733(62.9)$ & $450(61.4)$ & $283(38.6)$ \\
\hline Children 5 - 12 years & $21(12.4)$ & $10(47.6)$ & $11(52.4)$ & $138(11.8)$ & $82(59.4)$ & $56(40.6)$ \\
\hline Adults & $27(16.0)$ & $12(44.4)$ & $15(55.6)$ & $294(25.2)$ & $172(58.5)$ & $122(41.5)$ \\
\hline Pregnancy & & & 0 & & & $2(1.6)$ \\
\hline Total & $169(25.5)$ & $92(54.4)$ & $77(45.6)$ & $1165(47.4)$ & $704(60.4)$ & $461(39.6)$ \\
\hline Total cases in study & 662 & 226 & 436 & 2459 & 1192 & 1267 \\
\hline
\end{tabular}




\section{RESEARCH}

Table 4. Demographic data from the Tygerberg Hospital study and the Tygerberg PIC hospital-based cases study: Category of toxic exposure and most common exposures per category

\begin{tabular}{|c|c|c|}
\hline & $\begin{array}{l}\text { Tygerberg Academic Hospital } \\
\text { admissions, total cases (column \%) }\end{array}$ & $\begin{array}{l}\text { Tygerberg PIC hospital-based cases, } \\
\text { total cases (column \%) }\end{array}$ \\
\hline \multicolumn{3}{|l|}{ Exposures to medicines (pharmaceuticals) ${ }^{*}$} \\
\hline Children $<5$ years & $46(9.2)$ & $266(25.5)$ \\
\hline Children 5 - 12 years & $27(5.4)$ & $53(5.1)$ \\
\hline All children & $73(14.6)$ & $319(30.6)$ \\
\hline Adults & $427(85.4)$ & $723(69.4)$ \\
\hline Total medicines & $500(75.5)$ & $1042(42.4)$ \\
\hline \multicolumn{3}{|l|}{ Most common exposures to medicines } \\
\hline Analgesics & $260(52.0)$ & $339(32.5)$ \\
\hline Paracetamol & $136(27.2)$ & $189(18.1)$ \\
\hline Amitriptyline & $77(15.4)$ & $53(5.1)$ \\
\hline Antihistamines & $63(12.6)$ & $123(11.8)$ \\
\hline Benzodiazepines & $21(4.2)$ & $100(9.6)$ \\
\hline \multicolumn{3}{|l|}{ Exposures to NDCs } \\
\hline Children $<5$ years & $68(36.2)$ & $437(35.3)$ \\
\hline Children 5 - 12 years & $10(5.3)$ & $55(4.4)$ \\
\hline Adults & $110(58.5)$ & $747(60.3)$ \\
\hline Total NDCs & $188(28.4)$ & $1239(50.4)$ \\
\hline \multicolumn{3}{|l|}{ Most common exposures to NDCs } \\
\hline Pesticides $^{*+}$ & $59(31.4)$ & $493(39.8)$ \\
\hline Cholinesterase inhibitors & $34(18.1)$ & $168(13.6)$ \\
\hline Anticoagulant rodenticides & $13(6.9)$ & $87(7.0)$ \\
\hline Pyrethroids & $4(2.1)$ & $90(7.3)$ \\
\hline Ethanol as a co-ingested beverage & $47(25.0)$ & $49(3.4)$ \\
\hline Irritant/corrosives & $45(23.9)$ & $353(28.5)$ \\
\hline Volatile hydrocarbons & $30(16.0)$ & $141(11.4)$ \\
\hline \multicolumn{3}{|c|}{ Exposures to biological toxins (toxinological exposures) } \\
\hline Children $<5$ years & $2(18.2)$ & $36(17.6)$ \\
\hline Children 5 - 12 years & $3(27.3)$ & $25(12.6)$ \\
\hline Adults & $6(54.5)$ & $142(69.8)$ \\
\hline Total biologicals & $11(1.7)$ & $203(8.3)$ \\
\hline Snakebite & $4(36.4)$ & $67(33.0)$ \\
\hline Spider bite & $4(36.4)$ & $28(13.8)$ \\
\hline Scorpion sting & $3(27.3)$ & $28(13.8)$ \\
\hline Plants & 0 & $60(29.6)$ \\
\hline Exposures to other biological toxins & 0 & $20(9.9)$ \\
\hline Total cases in study & 662 & 2459 \\
\hline Total adults & 503 & 1574 \\
\hline Total children & 159 & 885 \\
\hline
\end{tabular}

Gastric decontamination measures were reported to the TPIC by hospital staff at the time of the call in $5.3 \%$ of cases (130). Single-dose activated charcoal was administered in $4.5 \%$ of cases (111); treatment was again non-compliant with international guidelines in $9.9 \%$ of these cases (11). MDAC was administered in 1 case. Gastric lavage was performed in 52 cases (2.1\%) and was inappropriate in $11.5 \%$ (6). 
Table 5. Clinical presentation of severe cases of poisoning and mortality data

\begin{tabular}{|c|c|c|c|c|c|c|}
\hline & \multicolumn{3}{|c|}{ Tygerberg Academic Hospital admissions } & \multicolumn{3}{|c|}{ Tygerberg PIC hospital-based cases } \\
\hline & $\begin{array}{l}\text { Total cases } \\
\text { (column \%) }\end{array}$ & $\begin{array}{l}\text { Adults } \\
\text { (row \%) }\end{array}$ & $\begin{array}{l}\text { Children } \\
\text { (row \%) }\end{array}$ & $\begin{array}{l}\text { Total cases } \\
\text { (column \%) }\end{array}$ & $\begin{array}{l}\text { Adults } \\
\text { (row \%) }\end{array}$ & $\begin{array}{l}\text { Children } \\
\text { (row \%) }\end{array}$ \\
\hline $\begin{array}{l}\text { PSS }=3 \text { (severe or life-threa } \\
\text { symptoms) }\end{array}$ & $90(13.6)$ & $72(80.0)$ & $18(20.0)$ & $190(7.7)$ & $153(80.5)$ & $37(19.5)$ \\
\hline Convulsions & $36(5.4)$ & $27(75.0)$ & $9(25.0)$ & $46(1.9)$ & $36(78.3)$ & $10(21.7)$ \\
\hline GCS $<9 / 15$ & $57(8.6)$ & $48(84.2)$ & $9(15.8)$ & $104(4.2)$ & $71(68.3)$ & $33(31.7)$ \\
\hline Intubated and ventilated & $23(3.5)$ & $22(95.7)$ & $1(4.3)$ & $27(1.1)$ & $26(96.3)$ & $1(3.7)$ \\
\hline PSS $=4$ (deaths) & $6(0.9)$ & 6 & & $11(0.4)$ & 11 & \\
\hline Aluminium phosphide & 0 & 0 & & 3 & 3 & \\
\hline Amitraz & 0 & 0 & & 2 & 2 & \\
\hline Corrosive & 0 & 0 & & 1 & 1 & \\
\hline Ethylene glycol & 1 & 1 & & 0 & 0 & \\
\hline Ferrous sulphate & 1 & 1 & & 0 & 0 & \\
\hline Organophosphate & 0 & 0 & & 1 & 1 & \\
\hline Orphenadrine & 1 & 1 & & 0 & 0 & \\
\hline Paraquat & 0 & 0 & & 1 & 1 & \\
\hline Ricinus communis seeds & 0 & 0 & & 1 & 1 & \\
\hline Theophylline & 2 & 2 & & 1 & 1 & \\
\hline Unknown pesticide & 1 & 1 & & 1 & 1 & \\
\hline Total cases in study & 662 & 503 & 159 & 2459 & 1574 & 885 \\
\hline
\end{tabular}

Syrup of ipecacuanha was administered to induce emesis in $0.7 \%$ of cases (17). Paracetamol levels were taken within 2 hours of ingestion in $3.7 \%$ of cases and NAC was administered inappropriately in 3 of 7 cases. Atropine was administered unnecessarily as the antidote in amitraz (10), glyphosate (1) and aluminium phosphide (1) poisoning (the latter both misdiagnosed as organophosphate poisoning due to 'phos' in the name).

\section{Discussion}

Comparing the trends in the two studies (Tables 2, 3 and 4), commonalities are a predominance of adult admissions, intentional poisoning (predominantly in adults), a female predominance among adults and those whose poisonings were intentional, a high incidence of paracetamol and cholinesterase inhibitor exposures, a predominance of paediatric exposures in the $<5$-year-old group, and male predominance and accidental exposures in this group. Other hospital admission studies have shown similar findings. ${ }^{[11-13]}$ Medicine-related poisoning was more common in TAH admissions than in the TPIC hospitalbased cases (75.5\% v. 42.4\%), and poisonings due to medicines used for pain control also featured more prominently. This finding could be expected, as it is anticipated that intentional exposures, particularly to pharmaceuticals, would result in a more serious toxic exposure, necessitating direct admission to hospital without first contacting a PIC. This would also apply to the finding that the incidence of exposure to paraffin in the $<5$-year-old group was higher in the TAH study (13.2\% v. 1.9\%). Non-drug chemical-related poisoning was more common in TPIC hospital-based consultations than medicine-related exposures. The importance of the identification of amitraz and aldicarb as toxicovigilance targets was illustrated in both sets of hospital data, as in our previous study. ${ }^{[9]}$

Disturbing findings specific to the TAH study and relevant to its catchment area are the high incidences of intentional poisoning in adult females, amitriptyline poisoning, and ethanol co-ingestion. The easy accessibility of amitriptyline (schedule 5) to this group of patients calls for an audit of hospital prescribing habits. Ethanol was the most common non-drug chemical exposure in the hospital study (25.0\%). A similar high incidence of ethanol co-ingestion has been reported elsewhere ${ }^{[11]}$ However, the unexpected finding that $76.6 \%$ of these cases were adult females, of whom $61.1 \%$ were of childbearing age, is cause for concern.

The time interval between exposure to a poisonous substance and the onset of clinical symptoms is an important window of opportunity for gastric decontamination interventions. ${ }^{[8]}$ Current international guidelines advise that administration of single-dose activated charcoal and gastric lavage should only be considered if the poison was ingested within 1 hour of presentation. ${ }^{[4,6,8]}$ While only $7.9 \%$ of patients in the TAH study presented within 2 hours of exposure to the poisonous substance, activated charcoal was administered to $34 \%$ of patients. In $20.3 \%$ of the cases in the TPIC hospital-based study the call was made to the PIC within 2 hours of the toxic exposure and activated charcoal administration was reported in $4.5 \%$ of cases. MDAC was administered inappropriately in the TAH study, and syrup of ipecacuana was used to induce emesis in hospitals in both studies although no longer recommended. ${ }^{[5,7,8,14}$ This survey has identified that some medical professionals remain unaware of the updated guidelines for gastric decontamination procedures and that directed training to familiarise them with the current recommendations is necessary. The important role of the TPIC in advising hospital staff on initial decontamination procedures cannot be overemphasised.

This survey has also revealed that the management of paracetamol poisoning was sub-optimal. This observation has been made elsewhere. ${ }^{[8,10,13,15]}$ Samples for blood levels were taken earlier than the recommended 4 hours after ingestion, and NAC was administered 
to patients with no history of a potentially hepatotoxic ingestion of paracetamol and before paracetamol levels were received from the toxicology laboratory. In other cases, the infusion was continued despite non-toxic paracetamol blood levels. Serum levels measured too early do not provide meaningful results indicating whether administration of the antidote is necessary or not. ${ }^{[1,15]}$ The expense of unnecessary administration, unnecessary prolongation of administration and limited availability of NAC in SA impact negatively on hospital and National Department of Health budgets. These observations, made early in the course of this study, identified the need for directed interventions at TAH, and continuing medical education (CME) on updated emergency management of poisoning was initiated. The TPIC posted standard operating procedures for the initial management of paracetamol poisoning and the correct protocol for the administration of NAC on noticeboards in the emergency wards. CME interventions such as presentations at local academic meetings and publication of guidelines for the emergency management of acute poisoning were also undertaken. ${ }^{[1] 6]}$

There are several limitations to this study. The data detailing TAH admissions are limited by the fact that they are restricted to the hospital feeder area and do not represent the national incidence and spectrum of poisonings. Other limitations of this study are those associated with the use of PIC data, and these are similar to those that pertained to our analysis of TPIC data. ${ }^{[9]}$ The decontamination procedures and use of antidotes reported by hospitals to the TPIC must be regarded as minimum frequencies because of the limitations of telephone data gathering. ${ }^{[14]}$

\section{Conclusion}

The combination of data from TAH admissions and TPIC hospitalbased consultations provided important information on trends in national hospital admissions for poisoning, the initial management of poisoning cases, and the spectrum of poisoning in SA. Medicinerelated poisonings, co-ingestion of ethanol and a predominance of female admissions were the most common characteristics of TAH admissions, whereas non-drug-related poisonings predominated in TPIC hospital cases. The most common findings in both sets of data, common to our previous findings, were: $(i)$ a predominance of adult exposures (mainly female); (ii) a predominance of intentional poisoning in adults (mainly female); (iii) a predominance of accidental exposures and male predominance in children aged $<5$ years; and (iv) a predominance of paracetamol and cholinesterase inhibitor exposures. ${ }^{\left[{ }^{[9]}\right.}$ These results can be interpreted as an indication of national trends in poisoning in SA.

Comparison of the results of this study with other similar published studies is limited as the true incidence of acute poisoning globally is uncertain, and there are few such studies reflecting the situation in other countries in Africa. However, age and gender demographics in the $<5$-year-old group, and the predominance of intentional poisoning and females in adult groups, do reflect similar patterns when compared with international reports. ${ }^{[1-14]}$ Lack of familiarity with the differential diagnosis and management of exposures to amitraz and aldicarb 'rat poison' were identified as ongoing toxicovigilance targets, as in our previous paper. ${ }^{[9]}$ Suboptimal initial management of poisoning was identified. It is hoped that this study will serve to alert authorities to the need for directed training on gastric decontamination procedures in the initial management of poisoning and the management of paracetamol poisoning, and that other hospitals will be encouraged to audit the management of acute poisoning cases in their emergency units.

Acknowledgements. We thank all the staff of the Tygerberg Poison Information Centre and the Toxicology Laboratory for their valuable contribution to this study.

Ethics approval. Ethics approval No. NO8/06/71 was given by the Stellenbosch University Committee for Human Research.

\section{References}

1. Meredith TJ. Epidemiology of Poisoning. Pharmacol Ther 1993;59:251-256.

2. Guidelines for Poison Control. http://www.who.int/ipcs/publications/training_poisons/guidelines _

Guidelines for Poison Control. http://www.who.int/pcis
poison_control/en/index 5 html (accessed 6 July 2012)

3. Krenzelok EP, Vale JA. Gastrointestinal decontamination. In: Brent J, Wallace KL, Burkhart KK Phillips SD, Donovan JW, eds. Critical Care Toxicology: Diagnosis and Management of the Critically Phillips SD, Donovan JW, eds. Critical Care Toxicology: Dia
Poisoned Patient. Philadelphia: Elsevier Mosby, 2005:53-71.

4. American Academy of Clinical Toxicology, European Association of Poisons Centres and Clinical Toxicologists. Position Paper: Single-dose activated charcoal. Clin Toxicol 2005;43(2):61-87. [http:// 1oxicologists. Position Paper: Single-dose activated charcoal. Clin Toxicol 2005;43(2):61-87. [http:/
dx.doi.org/10.1081/CLT-51867].

5. American Academy of Clinical Toxicology, European Association of Poisons Centres and Clinical . American Academy of Clinical Toxicology, European Association of Poisons Centres and Clinical
Toxicologists. Position Statement and Practice Guidelines on the Use of Multi-Dose Activated Charcoal in the Treatment of Acute Poisoning. Clin Toxicol 1999;37(6):731-751.

6. American Academy of Clinical Toxicology, European Association of Poisons Centres and Clinical American Academy of Clinical Toxicology, European Association of Poisons Centres and Clinical
Toxicologists. Position Paper: Gastric lavage. Clin Toxicol 2004;42(7):933-943. [http://dx.doi. Toxicologists. Position Paper: Gastric lavage. Clin Toxicol 2004;42(7):933-943. [http://dx.doi.
org/10.1081/CLT-200045006].

American Academy of Clinical Toxicology, European Association of Poisons Centres and Clinica loxicologists. Position paper: Ipecac syrup. J Toxicol Clin Toxicol 2004;42(2):133-143. [http://dx.dol org/10.1081/CLT-120037421]

Good AM, Kelly CA, Bateman N. Differences in treatment advice for common poisons by poisons centres - an international comparison. Clin Toxicol 2007;45:234-239. [http://dx.doi. org/10.1080/15563650601031601]

Veale DJH, Wium CA, Müller GJ. Toxicovigilance I: A survey of acute poisonings in South Africa based on Tygerberg Poison Information Centre data. S Afr Med J 2013;103(5):293-297. [http://dx.doi org/10.7196/SAMJ.6647]

10. Daly FFS, Fountain JS, Murray L, Graudins A, Buckley NA. Guidelines for the management of paracetamol poisoning in Australia and New Zealand - explanation and elaboration. Med J Aust 2008; 188(5):296-301

11. Doak MW, Nixon AC, Lupton DJ, Waring WS. Self-poisoning in older adults: patterns of drug ingestion and clinical outcomes. Ageing 2009;38:407-411. [http://dx.doi.org/10.1093/ageing/afp046] 2. Tagwireyi D, Ball DE, Nhachi CFB. Poisoning in Zimbabwe: a survey of eight major referral hospitals. J Appl Toxicol 2002;22:99-105. [http://dx.doi.org/10.1002/jat.832]

13. Prescott K, Stratton R, Freyer A, Hall I, Le Jeune I. Detailed analysis of self-poisoning episodes presenting to a large regional teaching hospital in the UK. Br J Clin Pharmacol 2009;68(2):260-268 [http://dx.doi.org/10.1111/j.1365-2125.2009.03458.x]

14. Watson WA, Litovitz TL, Rodgers GC, et al. 2004 Annual Report of the American Association of Poison Control Centers Toxic Exposure Surveillance System. Am J Emerg Med 2005;23:589-666. [http://dx.doi.org/10.1016/j.ajem.2005.05.001]

15. Hayes BD, Klein-Swartz W, Doyon S. Frequency of medication errors with intravenous acetylcysteine for acetaminophen overdose. Ann Pharmacother 2008;42:766-770. [http://dx.doi.org/10.1345/ aph.1K685]

16. Van Hoving DJ, Veale DJH, Muller GJ. Emergency management of acute poisoning. African Journal of Emergency Medicine 2011;1:69-78. [http://dx.doi.org/10.1016/j.afjem.2011.07.006].

Accepted 24 December 2012 